\title{
Seguiment i actualització dels materials d'avaluació psicològica i psicopedagògica de la docimoteca de la Universitat Jaume I
}

\author{
AIDA SANAHUJA RIBÉS \\ asanahuj@uji.es \\ Odet MOLINER GaRcía \\ molgar@uji.es
}

\section{Resum}

La docimoteca és un servei que ofereix la Biblioteca de la Universitat Jaume I, consistent en una sala on es localitza el material psicotècnic, d'avaluació psicològica, psicoeducativa i d'intervenció. Aquest material es troba ordenat i classificat, amb l'objectiu de facilitar el seu ús com a sala de consulta i laboratori. En aquest estudi es dóna a conèixer el servei i es presenta el seguiment de la quantia de proves prestades i de consultes realitzades pels diferents usuaris. Es comptabilitza el nombre d'usos de perfils en línia i els usos de material fungible que s'han emprat en el curs acadèmic 2013/2014. Es presenten els qüestionaris que s'han incorporat a la docimoteca arran del projecte «Recerca de materials d'avaluació psicològica i psicoeducativa no comercialitzats». La mostra d'aquest estudi està formada pel professorat dels departaments de Psicologia i d'Educació, l'alumnat autoritzat dels màsters de les àrees de psicologia i d'educació, l'alumnat autoritzat de grau o llicenciatura de les titulacions de magisteri, psicopedagogia i psicologia i el personal extern a la universitat que ha fet ús del servei en el període de temps estudiat. L'estudi mostra que la major part dels préstecs s'han realitzat al personal extern de l'UJl, mentre que l'alumnat és qui més consultes ha realitzat.

Paraules clau: servei bibliotecari, docimoteca, tests, materials d'avaluació, materials d'intervenció.

\begin{abstract}
The Test Library is a service offered by the library of the Universitat Jaume I, consisting of a room where the psychotechnical material, the psychological and psychoeducational assessment material and also the intervention material are located. All this material is also organized and classified there, with the objective of its use as a consulting room and laboratory. This study discloses the Test Library service. In this study it is monitored the amount of borrowed tests and also the consultations conducted by different
\end{abstract}

Agraïments. La realització d'aquest article ha estat possible gràcies a la beca de col·laboració «Recerca de materials d'avaluació psicològica i psicoeducativa no comercialitzats» (convocatòria 2013, Universitat Jaume I), que ha estat concedida a la primera autora. 
users. The number of uses of online profiles and the uses of consumables that have been used in the academic year 2013/2014 are accounted for. And the questionnaires that have been added conforming to the guidelines of the project of «Search of Psychological and Psychoeducational Assessment Materials non-marketed» (Recerca de materials d'avaluació psicològica i psicoeducativa no comercialitzats) are presented. The sample of this study is composed by the faculty of the Departments of Psychology and Education, the students of Master's degree in the areas of Psychology and Education, students of degrees in Education, Psychopedagogy and Psychology or students of the Licenciatura $^{1}$ degrees in the same areas of study and also the external staff at the university. All of them have made use of the service in the time period studied. The study shows that the external staff in the UJI are the users who more loans have made, while pupils are who more inquiries have made.

Keywords: Library service, Test Library, tests, assessment material, intervention materials.

\section{Introducció}

Etimològicament el terme docimoteca prové del grec dokimázo, que significa 'assajar'. Aquest espai tracta de recollir els instruments d'avaluació (tests, escales, bateries, qüestionaris, etc.) i d'intervenció utilitzats per a la detecció de problemes o característiques especials d'un individu o d'un col·lectiu determinat (Olaran, 2011). Respecte de la universitat on s'ubica, compleix amb la funció interna de suport a la docència i a la investigació, i ofereix una col·lecció estretament relacionada amb els programes d'estudi, concretament amb els de psicologia i educació, i tracta de satisfer les demandes d'informació dels usuaris, als quals permet formarse, investigar i diagnosticar problemes o característiques especials, tant en l'àmbit clínic com en l'educatiu (Olaran, 2010).

L'article 35 del capítol IX del Reglament del servei de la biblioteca de la Universitat Jaume I (aprovat en la sessió núm. 20 del Consell de Govern del dia 25 de juny de 2008) estableix que «la docimoteca és un servei que ofereix la Biblioteca de l'uJl, consistent en una sala on es localitza, ordena i classifica el material psicotècnic, d'avaluació psicològica i psicoeducativa i d'intervenció, a l'objecte del seu ús com a sala de consulta i laboratori».

Quant a la consulta i el préstec de material, és necessari destacar que la consulta del material s'ha de realitzar en la mateixa sala de la docimoteca. El préstec està restringit només a les persones autoritzades, és a dir, té limitacions deontològiques que impedeixen la plena difusió dels documents. Amb la finalitat d'assegurar una utilització correcta dels tests, l'APA (American Psychological Association's) va establir unes normes posteriorment adoptades pel Col-legi Oficial de Psicòlegs espanyol, les quals limiten l'accés als tests en funció de la formació i de la titulació de l'usuari. ${ }^{2}$ Per aquest motiu el fons ha d'estructurar-se en fons d'accés restringit (Olaran, 2011). Tal com assenyala l'article 36 del reglament anteriorment esmentat, són usuaris del servei de docimoteca:

1. Licenciatura: In Spain, this kind of degree was one of the major higher-education degrees previous to doctoral studies, and is equivalent to a Master's degree in the Anglophone system. This degree is currently being phased out at Spanish universities, replaced by the 'Grado' (Bachelor) and 'Master' system due to the implementation of the Bologna Declaration on the European higher education area.

2. Cada vegada que s' esmente usuari, director, etc., s'entén que es fa referència a ambdós sexes indistintament. 
- El professorat dels departaments de psicologia i d'educació.

- Els estudiants que autoritze el professorat dels departaments de psicologia i d'educació.

- Professionals titulats en els camps de la psicologia i la pedagogia (personal extern). A més, aquests han de ser membres de SAUJI (Societat d'Amics i Antics Alumnes de I'UJI). ${ }^{3}$

- Tots aquells usuaris que siguen autoritzats pel director del projecte de la docimoteca.

Tal com estableix Olaran (2010), el material propi de la docimoteca és d'una tipologia documental molt específica, és car i delicat, amb un procés tècnic molt costós, ja que el seu ús ha de ser rigorós. El conjunt del material que podem trobar a la docimoteca de l'UJI són tests, escales, bateries, qüestionaris de les diferents temàtiques de la psicologia i la psicopedagogia, com ara: ansietat, aprenentatge, autoestima-autorealització, cognició, conducta, creativitat, depressió, dol, drogoaddicció, educació especial, educació infantil, emocions, família, geriatria, habilitats socials, intel-ligència, lectura i escriptura, llenguatge, neuropsicologia, orientació professional, percepció, personalitat, psicomotricitat, salut i qualitat de vida, tècniques d'estudi, tècniques de relaxació, trastorns de conducta alimentària, trastorns sexuals, reball, violència i redacció d'informes. A més a més, també es disposa de material d'intervenció. La recerca específica es fa mitjançant el catàleg general de la biblioteca de l'UJ. ${ }^{4}$

El personal encarregat de la docimoteca desenvolupa les tasques següents:

- Tenir cura dels instruments d'avaluació i mantenir-los aptes per a l'ús, vetllar per la seua adequada utilització i donar suport a les pràctiques docents que utilitzen instruments d'avaluació.

- Gestionar els fulls d'autorització per a la sol-licitud de préstecs de test, autoritzacions especials, sol-licitud d'usos i perfils en línia i sol-licitud de material fungible per a les pràctiques docents.

- Assessorar i posar a la disposició de qui els sol-licite, els materials, tant per a la consulta com per al préstec d'aquests. És necessari remarcar que quan el material és retirat en préstec, cada usuari disposa d'un temps i d'un nombre de proves diferent. L'alumnat autoritzat pot agafar una prova durant tres dies, el personal extern pot agafar dues proves durant una setmana i el professorat pot agafar fins a tres proves durant dues setmanes.

- Preparar l'accés a les plataformes automatitzades (TEA i PEARSON), contractant i descarregant els usos per a la correcció automatitzada en línia.

- Recerca d'instruments d'avaluació per la web, per iniciativa i per demanda.

- Difondre el servei de la docimoteca entre els usuaris interns a l'UJI i els usuaris externs a l'UJ (professionals de la psicologia, psicopedagogia i de l'educació).

- Realitzar els estudis necessaris, l'elaboració de projectes i la negociació amb responsables de departaments i serveis pertinents.

- Mantenir activa la base de dades per al control del material.

- Realitzar la memòria final de curs. 


\section{Mètode}

Presentem un estudi descriptiu i de seguiment de l'ús de la docimoteca, els objectius del qual són:

- Donar a conèixer el servei de la docimoteca de la Universitat Jaume I.

- Fer un seguiment de la quantia de proves prestades als diferents usuaris des de setembre de 2013 fins a juny de 2014.

- Realitzar un seguiment del nombre de consultes realitzades pels diferents usuaris des de novembre de 2013 fins a juny de 2014.

- Comptabilitzar el nombre d'usos de material fungible i els usos de perfils en línia que s'han emprat des de setembre de 2013 fins a juny del 2014.

- Presentar els qüestionaris que s'han incorporat arran del projecte «Recerca de materials d'avaluació psicològica i psicoeducativa no comercialitzats».

La mostra d'aquest estudi està formada pels usuaris que han fet ús del servei des de setembre de 2013 fins a juny de 2014.

La recollida de dades s'ha realitzat mitjançant els fulls que emplenen els usuaris de la docimoteca cada vegada que fan una sol-licitud de préstec de material, una sol-licitud de material fungible per a pràctiques docents o una sol-licitud d'usos de perfil i informes en línia. ${ }^{5}$ Les dades s'han recollit cada mes i s'han vesat al programa Excel.

El període de recollida de les consultes realitzades abasta des de novembre del 2013 fins a juny de 2014 (coincidint en el període de beca).

A més, des de la docimoteca es va portar a terme el projecte de «Recerca de materials d'avaluació psicològica i psicoeducativa no comercialitzats». Mitjançant correu electrònic es va sol-licitar al professorat dels departaments d'educació, psicologia bàsica i psicologia evolutiva que feren arribar a la docimoteca, en format paper o electrònicament, qualsevol tipus d'instrument o qüestionari que hagueren construït però amb la condició que no estigueren comercialitzats.

\section{Resultats}

En aquest apartat presentarem: el nombre de préstecs realitzat, el nombre de consultes, el nombre de material fungible sol-licitat, el nombre d'usos de perfils en línia sol-licitat i els nous materials no comercialitzats que s'han incorporat.

A continuació, es presenta la taula 1 on es recull el nombre de préstecs realitzat atenen al mes i el tipus d'usuari de la docimoteca. 
Taula 1

Nombre de préstecs segons el tipus d'usuari i mes

\begin{tabular}{cccccc}
\hline Mes & $\begin{array}{c}\text { Préstec } \\
\text { personal extern }\end{array}$ & $\begin{array}{c}\text { Préstec } \\
\text { professorat }\end{array}$ & $\begin{array}{c}\text { Préstec } \\
\text { alumnat màster }\end{array}$ & $\begin{array}{c}\text { Préstec } \\
\text { alumnat }\end{array}$ & Total \\
\hline set-13 & 21 & 6 & 3 & 6 & 36 \\
oct-13 & 46 & 22 & 25 & 16 & 109 \\
nov-13 & 59 & 28 & 0 & 13 & 100 \\
des-13 & 20 & 9 & 4 & 69 & 102 \\
gen-14 & 67 & 32 & 6 & 16 & 121 \\
feb-14 & 101 & 39 & 20 & 6 & 166 \\
març-14 & 76 & 33 & 10 & 9 & 128 \\
abr-14 & 68 & 54 & 7 & 17 & 146 \\
maig-14 & 85 & 27 & 2 & 87 & 201 \\
juny-14 & 62 & 31 & 1 & 23 & 117 \\
\hline Total & 605 & 281 & 78 & 262 & 1.226 \\
\hline
\end{tabular}

Des de setembre de 2013 fins a juny de 2014, s'han realitzat un total 1.226 préstecs en la docimoteca de la Universitat Jaume I. Concretament s'han realitzat 605 préstecs a personal extern, 281 préstecs a professorat de l'àrea de psicologia i de l'educació de l'UJ, 78 préstecs a alumnes de màster i 262 préstecs a alumnes de grau o llicenciatura de les titulacions de magisteri, psicopedagogia i psicologia.

Durant el mes de setembre es van prestar un total de 36 materials. Concretament, es van fer 21 préstecs al personal extern, 6 préstecs al professorat, 3 préstecs a alumnes de màster i 6 préstecs a alumnes de grau o llicenciatura.

En octubre es van prestar un total de 109 materials dels quals 46 préstecs eren a personal extern, 22 préstecs al professorat, 25 préstecs a alumnes de màster i 16 préstecs a alumnes de grau o llicenciatura.

En novembre es van prestar un total de 100 materials: 59 a personal extern, 28 a professorat i 13 a alumnat de grau o llicenciatura.

Durant el mes de desembre es van prestar un total de 102 materials, 20 dels quals eren a personal extern, 9 préstecs al professorat, 4 préstecs a alumnat de màster i 69 préstecs a alumnat de grau o llicenciatura.

Al mes següent, gener, es van prestar 121 materials (67 a personal extern, 32 al professorat, 6 a alumnat de màster i 16 a alumnat de grau o llicenciatura).

Durant el mes de febrer es van prestar un total de 166 materials. Concretament, es van fer 101 préstecs al personal extern, 39 préstecs al professorat, 20 préstecs a alumnes de màster i 6 préstecs a alumnes de grau o llicenciatura.

En març es van prestar un total de 128 materials (76 préstecs al personal extern, 33 préstecs al professorat, 10 préstecs a alumnes de màster i 9 préstecs a alumnes de grau 0 llicenciatura).

Al mes d'abril es van prestar 146 materials, 68 dels quals eren a personal extern, 54 préstecs al professorat, 7 préstecs a alumnes de màster i 17 préstecs a alumnes de grau 0 llicenciatura. 
Al maig es van prestar un total de 201 materials. Concretament, es van fer 85 préstecs al personal extern, 27 préstecs al professorat, 2 préstecs a alumnes de màster i 87 préstecs a alumnes de grau o llicenciatura.

Per acabar, durant el mes de juny es van prestar un total de 117 materials (62 préstecs al personal extern, 31 préstecs al professorat, 1 préstec a un alumne de màster i 23 préstecs a alumnes de grau o llicenciatura).

En la figura 1, que es presenta a continuació, es pot veure de manera gràfica les dades anteriorment descrites.

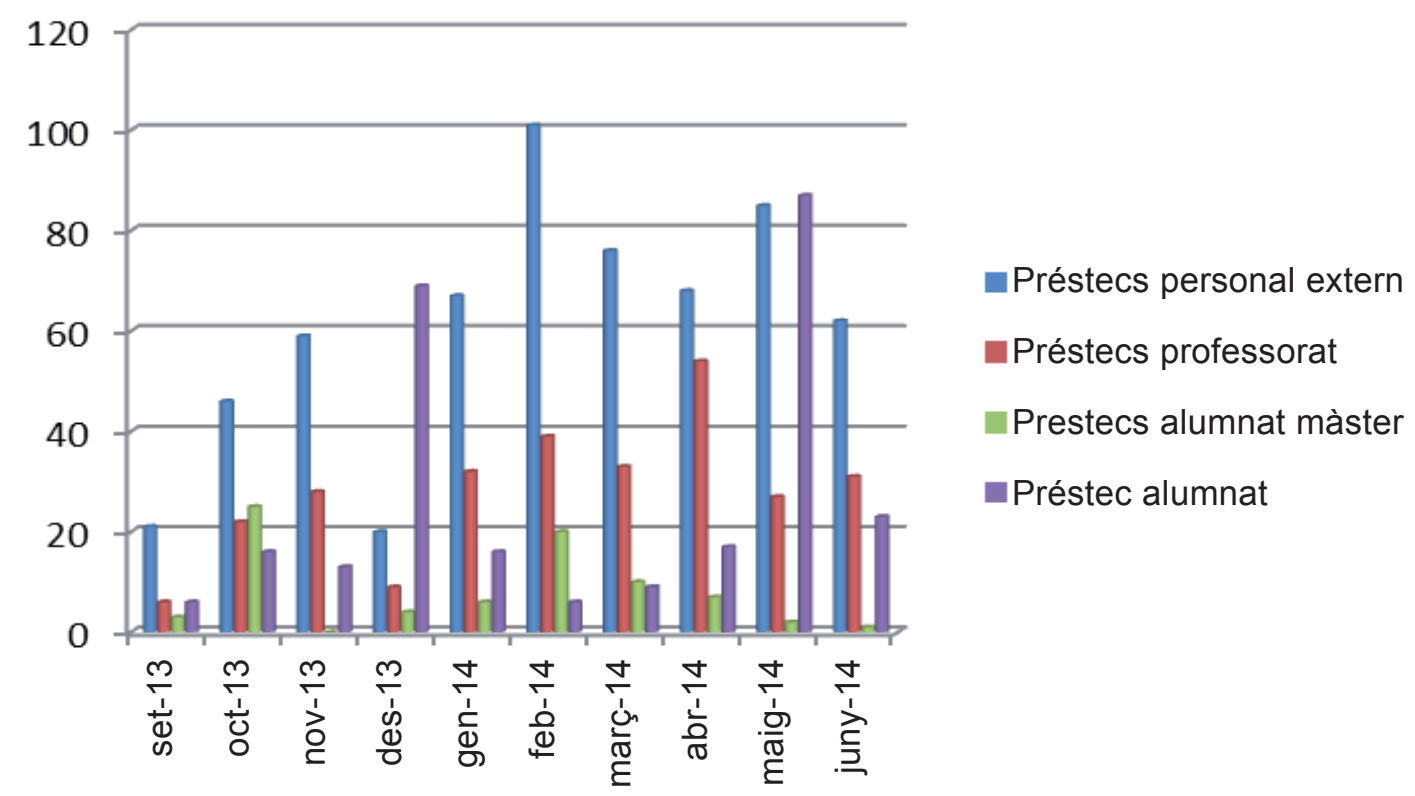

Figura 1. Nombre de préstecs segons el tipus d'usuari i mes

Seguidament es presenta la taula 2, on es recull el nombre de consultes realitzades atenen al mes i el tipus d'usuari de la docimoteca.

Taula 2

Nombre de consultes segons el tipus d'usuari i mes

\begin{tabular}{cccccc}
\hline Mes & $\begin{array}{c}\text { Consultes } \\
\text { personal extern }\end{array}$ & $\begin{array}{c}\text { Consultes } \\
\text { professorat }\end{array}$ & $\begin{array}{c}\text { Consultes } \\
\text { alumnat màster }\end{array}$ & $\begin{array}{c}\text { Consultes } \\
\text { alumnat }\end{array}$ & Total \\
\hline nov-13 & 1 & 0 & 0 & 9 & 10 \\
des-13 & 4 & 1 & 2 & 10 & 17 \\
gen-14 & 45 & 11 & 1 & 26 & 83 \\
feb-14 & 53 & 7 & 33 & 32 & 125 \\
març-14 & 21 & 0 & 6 & 17 & 44 \\
abr-14 & 3 & 0 & 6 & 14 & 23
\end{tabular}




\begin{tabular}{cccccc}
\hline Mes & $\begin{array}{c}\text { Consultes } \\
\text { personal extern }\end{array}$ & $\begin{array}{c}\text { Consultes } \\
\text { professorat }\end{array}$ & $\begin{array}{c}\text { Consultes } \\
\text { alumnat màster }\end{array}$ & $\begin{array}{c}\text { Consultes } \\
\text { alumnat }\end{array}$ & Total \\
\hline maig-14 & 23 & 5 & 0 & 127 & 155 \\
juny-14 & 24 & 0 & 1 & 34 & 59 \\
\hline Total & 174 & 24 & 49 & 269 & 516 \\
\hline
\end{tabular}

Tal com es pot observar a la taula 2, s'han realitzat un total de 516 consultes, des de novembre de 2013 fins a juny de $2014 .{ }^{6}$ Concretament s'han realitzat 174 consultes per part del personal extern, 24 per part del professorat de l'àrea de psicologia i de l'educació de l'UJ, 49 per part dels alumnes de màster i 269 per part dels alumnes de grau o llicenciatura de les titulacions de magisteri, psicopedagogia i psicologia.

Al novembre es van fer 10 consultes: només 1 consulta per part del personal extern i 9 consultes per part del l'alumnat de grau o llicenciatura.

Durant el mes de desembre es van fer un total de 17 consultes. Concretament, 4 van ser de personal extern, 1 per part d'un professor, 2 per part dels alumnes de màster i 10 per part dels alumnes de grau o llicenciatura.

Durant el mes de gener es van fer un total de 83 consultes, la major part de les quals (45) van ser realitzades per part del personal extern, 11 per part del professorat, 1 per part d'un alumne de màster i 26 per part dels alumnes de grau o llicenciatura.

Durant el mes de febrer va haver-hi 125 consultes de les quals 53 les va fer el personal extern, 7 el professorat, 33 l'alumnat de màster i 32 els alumnes de grau o llicenciatura.

Al març es van fer un total de 44 consultes. Concretament, es van fer 21 consultes per part del personal extern, 6 per part dels alumnes de màster i 17 per part dels alumnes de grau o llicenciatura.

Al mes d'abril el total de consultes va ser de 23. Només 3 van ser per part del personal extern, 6 per part dels alumnes de màster i 14 per part dels alumnes de grau o llicenciatura.

Durant el mes de maig es van fer un total de 155 consultes. Concretament, es van fer 23 consultes per part del personal extern, 5 per part del professorat i 127 per part dels alumnes de grau o llicenciatura.

Finalment, al mes de juny es van fer un total de 59 consultes, de les quals 24 van ser de personal extern, 1 per part d'un alumne de màster i 34 de l'alumnat de grau o llicenciatura.

A continuació es presenta la figura 2 en la qual s'observen de manera gràfica les dades anteriorment descrites.

6. Les consultes fan referència als mesos de novembre del 2013 a juny del 2014 , ja que com s'ha esmentat abans és el període en el qual la becaria va estar en la docimoteca. 


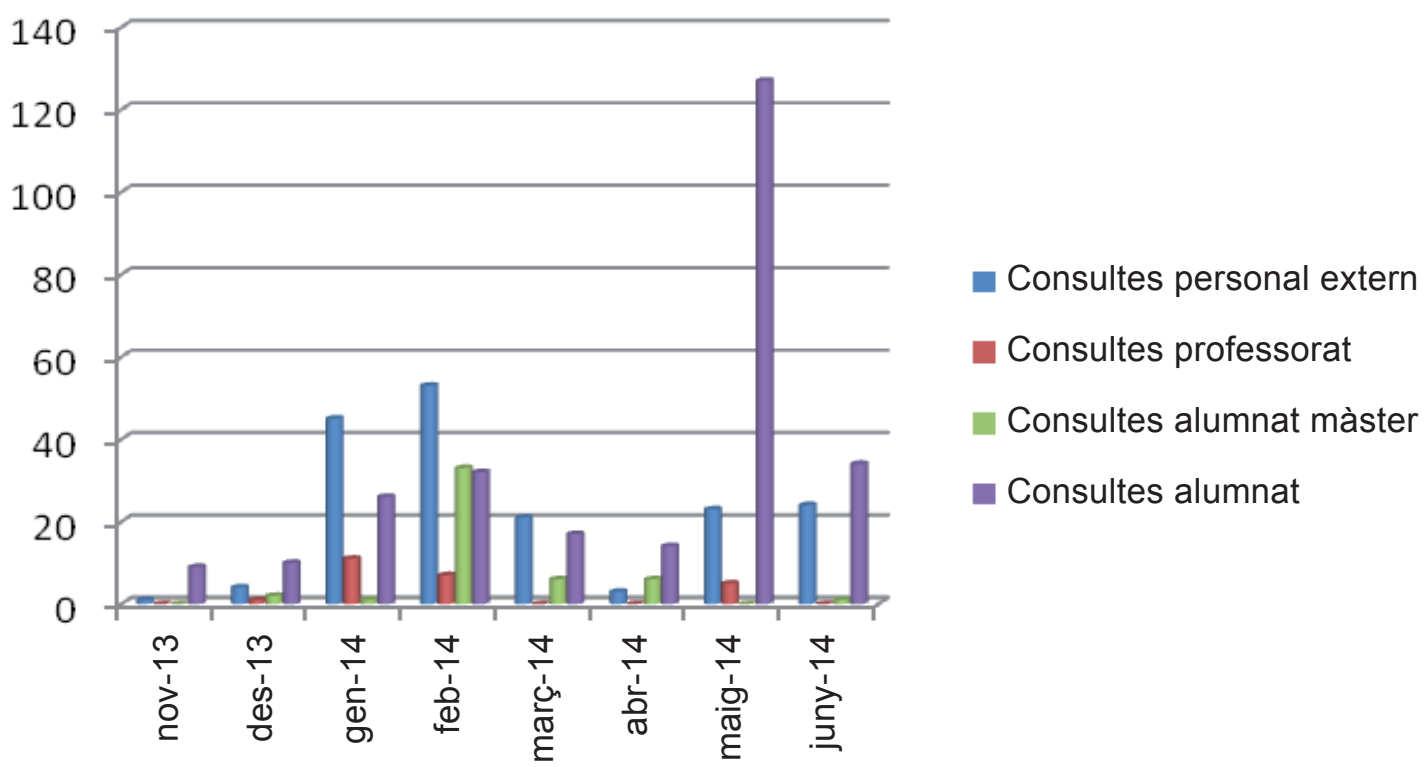

Figura 2. Nombre de consultes segons el tipus d'usuari i mes

Tot seguit s'aborda, en la taula 3, la distribució del nombre de material fungible sol-licitat en els diferents mesos. Durant el període estudiat s'han realitzat un total de 1.128 sol-licituds de materials fungibles.

Taula 3

Nombre de material fungible sol/licitat segons el mes

\begin{tabular}{cc}
\hline Mes & Material fungible \\
\hline set-13 & 6 \\
oct-13 & 400 \\
nov-13 & 38 \\
des-13 & 39 \\
gen-14 & 59 \\
feb-14 & 223 \\
març-14 & 24 \\
abr-14 & 226 \\
maig-14 & 65 \\
juny-14 & 48 \\
\hline Total & 1.128 \\
\hline
\end{tabular}

Com podem veure en la taula 3 , al mes de setembre es van sol-licitar un total de 6 materials fungibles; a l'octubre, 400; al novembre, 38; al desembre, 39; al gener, 59; al febrer, 223; al març, 24; a l'abril, 226; al maig, 65; i al juny, 48. 
En la figura 3, que es presenta a continuació, es poden veure de manera gràfica les dades anteriorment descrites.

\section{Material fungible}

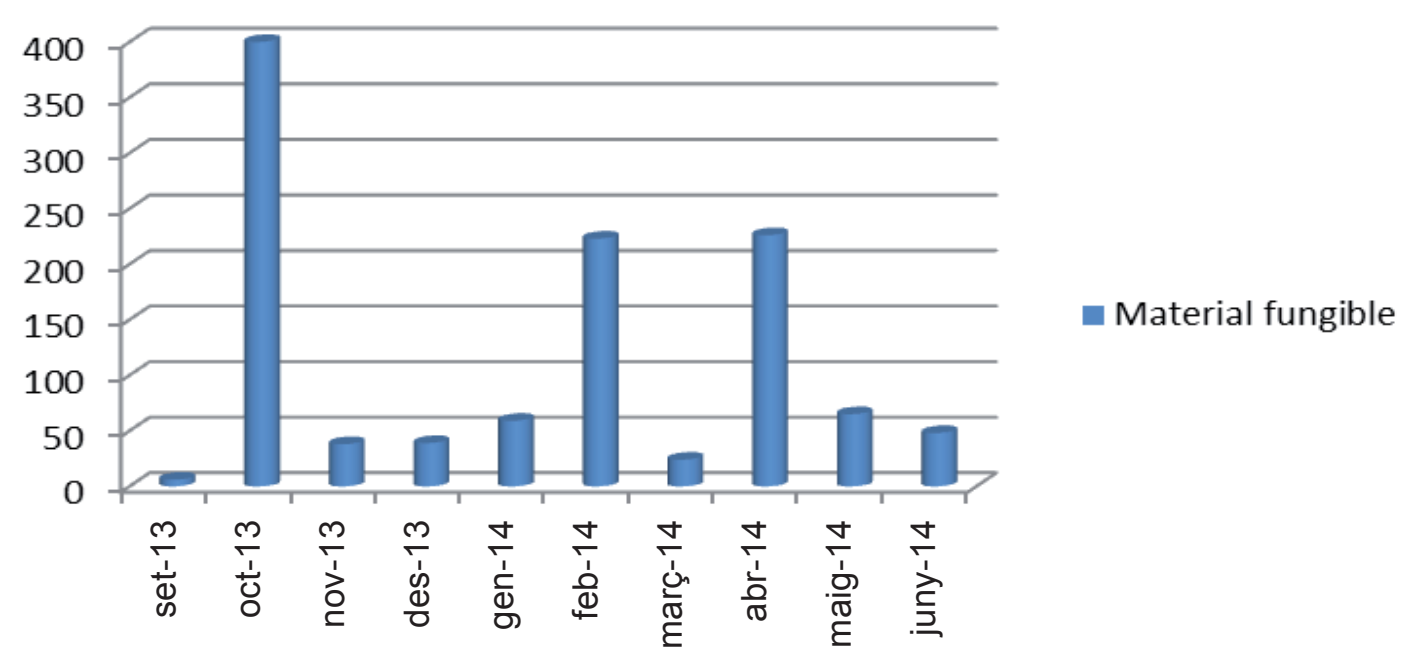

Figura 3. Nombre de material fungible sol·licitat segons el mes

Com es pots observar en la taula 4, s'han emprat un total de 153 usos de perfils i informes en línia.

Taula 4

Nombre d'usos de perfils en línia sol-licitat segons el mes

\begin{tabular}{cc}
\hline Mes & Usos perfils \\
\hline set-13 & 0 \\
oct-13 & 0 \\
nov-13 & 7 \\
des-13 & 42 \\
gen-14 & 12 \\
feb-14 & 10 \\
març-14 & 18 \\
abr-14 & 15 \\
maig-14 & 14 \\
juny-14 & 35 \\
\hline Total & 153 \\
\hline
\end{tabular}


Tal com podem veure en la taula 4 , al mes de novembre es van utilitzar un total de 7 usos de perfils; al desembre, 42; al gener, 12; al febrer, 10; al març, 18; a l'abril, 15; al maig, 14; i al juny, 35.

En la figura 4, que es presenta a continuació, es poden veure de manera gràfica les dades anteriorment descrites.

\section{Usos perfils}

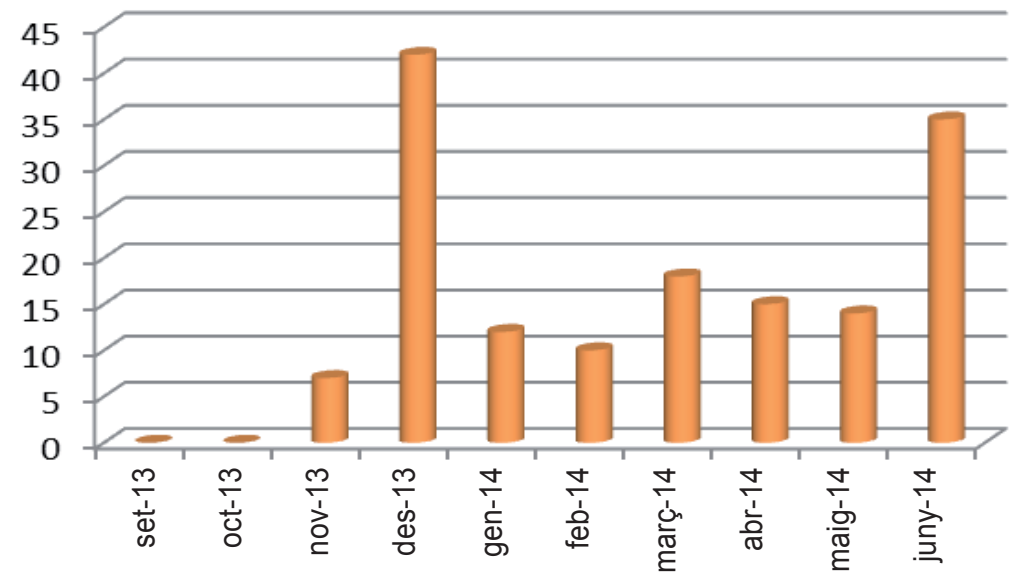

Usos perfils

Figura 4. Nombre d'usos de perfils en línia sol·licitat segons el mes

Per acabar amb aquest apartat, val a dir que s'hi han incorporat 17 materials d'avaluació psicològica i psicopedagògica no comercialitzats proporcionats per part del professorat i investigadors dels departaments de psicologia i d'educació de la Universitat Jaume I. Els materials han estat els següents:

Ballester, R. y cols. (2010). Propiedades psicométricas de un instrumento de evaluación de la adicción al cibersexo.

Ballester, R. y cols. (2013). Sexual Compulsivity Scale: Adaptation and Validation in the Spanish Population.

Booth, T. y Ainscow, M. (2002). Índex per a la inclusió. Guia per a l'avaluació i la millora de l'educació inclusiva.

Camacho, L. y cols. (2013). Spanish adaptation of the Expectancy Questionnaire (EQ) about alcohol effects in adolescents.

Doménech, A. y Moliner, O. (2011). Cuestionario-escala para familias sobre educación inclusiva (CEFEI).

Doménech, F. (2003). Creencias psicopedagógicas del profesorado sobre el proceso de enseñanza/aprendizaje. Primaria, secundaria y bachillerato.

Doménech, F. (2003). Elementos mediadores entre pensamiento y acción docente. Primaria, secundaria y bachillerato.

Doménech, F. (2003). Registro del estilo docente del profesor. Primaria, secundaria y bachillerato.

Mezquita, L. y cols. (2011). Drinking motives in clinical and general populations (DMQ-R). 
Moliner, O. y García R. (1994). Cuestionario-Escala sobre conocimientos y actitudes de los estudiantes hacia el sida y su prevención.

Sales, A. y García R. (1995). Cuestionario sobre educación intercultural y actitudes hacia la diversidad cultural para profesores de educación primaria y secundaria.

Sales, A. (1997). Cuestionario-Escala de actitudes interculturales para alumnos de 10 a 12 años.

Sales, A. (1997). Cuestionario-Escala de actitudes interculturales para alumnos de 12 a 16 años.

Sales, A. y cols. (2001). Encuesta de opinión para estudiantes de magisterio sobre atención a la diversidad.

Sales, A. y cols. (2004). Cuestionario profesores. Estudio sobre las actitudes hacia los alumnos con necesidades educativas especiales derivadas de discapacidad.

Sales, A. y cols. (2004). Cuestionario familias. Estudio sobre las actitudes hacia los alumnos con necesidades educativas especiales derivadas de discapacidad.

Traver, J. A. y cols. (2012). Preparing the Future of Schooling. Attitudes of Teacher Education Students Towards Educational Innovation.

\section{Discussió i conclusions}

Els resultats revelen que els principals usuaris d'aquest servei que ofereix la biblioteca de la Universitat Jaume I són el personal extern, és a dir, professionals de l'àrea de psicologia i de l'educació. El préstec de materials al professorat de l'UJl es més o menys constant al llarg del any, i és al setembre quan menys préstecs es realitzen i a l'abril quan més. Respecte dels préstecs realitzats als alumnes de grau o llicenciatura, cal remarcar que el màxim nombre de material prestat coincideix en els mesos de desembre i maig quan aquests realitzen els treballs finals de diferents assignatures, coincidint amb l'acabament del semestre.

Pel que fa a les consultes, els alumnes de grau o llicenciatura són els que més nombre de consultes han fet. Cal recordar que molts alumnes no autoritzats no poden retirar el material i per tant molts opten per treballar a la sala de la docimoteca.

Quant a les sol-licituds de material fungible, és necessari remarcar que el mes d'octubre és amb diferència el mes que s'han fet més sol-licituds seguits d'abril i febrer. El mes que menys sol-licituds de material fungible s'han realitzat ha sigut el mes de setembre. Açò es deu al fet que alguns professors retiren material fungible per a les pràctiques d'aula d'algunes assignatures de psicologia o psicopedagogia.

Referent als usos de perfil, cal dir que els mesos de desembre i juny són els mesos que més correccions en línia s'han realitzat.

S'hi han incorporat 17 materials nous, que es poden trobar al catàleg de la biblioteca i estan disponibles per a ser prestats als usuaris autoritzats que ho sol-liciten. Des d'aquestes línies volem agrair al professorat que ens ha fet arribar qüestionaris i escales no comercialitzades, la seua participació en el projecte d'actualització de materials.

Tot i que els objectius d'aquest estudi s'han complert, aquest podria tindre diverses vies de continuació. Una via de continuació aniria en la línia de fer un seguiment del nom o temàtica dels diferents materials o proves prestats, així com del nom o temàtica dels materials consultats en la sala, del nom o temàtica dels materials fungibles sol-licitats de cada prova $i$ del nom o temàtica dels usos de perfil o informes en línia utilitzats de cada prova. Açò ens permetria saber quins materials o proves són els més emprats per cada tipus d'usuaris del servei. 


\section{Referències bibliogràfiques}

Biblioteca-Centre de Documentació: La docimoteca. Recuperat l'1 de juliol de 2014, de: http:// ujiapps.uji.es/serveis/cd/bib/serveis/docimoteca/.

Consejo Central de Colegios Oficiales de Psicólogos. Código Deontológico del Psicólogo. Recuperat el 14 d'octubre de 2014, de: http://www.cop.es/pdf/Codigo-Deontologico-Consejo-Adaptacion-Ley-Omnibus.pdf.

Olaran, M. (2010). Implantación de un Nuevo Servicio: Docimoteca Especializada en Educación. En: Congresso Nacional de la Associaçao Portuguesa de Bibliotecários, Archivistas e Documentalistas (10. 2010. Guimaraes).

Olaran, M. (2011). ¿Dónde encontrar los instrumentos de evaluación? En la docimoteca universitaria. Mi biblioteca, 26, 64-66.

Reglament del servei de la biblioteca de la Universitat Jaume I. Recuperat el 9 d'octubre, 2013, de: http://www.uji.es/bin/uji/norm/reglaments/biblio.pdf. 